\title{
3 Research Suare \\ Practical Consideration For Successful Sequential Tumor Biopsies In First-In-Human Trials
}

\section{Takafumi Koyama}

National Cancer Center Hospital https://orcid.org/0000-0001-5807-8458

\section{Toshio Shimizu}

National Cancer Center Hospital

Jun Sato

National Cancer Center Hospital

Yuki Katsuya

National Cancer Center Hospital

Satoru Iwasa

National Cancer Center Hospital

Shunsuke Kondo

National Cancer Center Hospital

Tatsuya Yoshida

National Cancer Center Hospital

Kazuki Sudo

National Cancer Center Hospital

Makoto Nishino

National Cancer Center Hospital

Yuichi Takiguchi

Chiba University

Kan Yonemori

National Cancer Center Hospital

Noboru Yamamoto ( $\nabla$ nbryamam@ncc.go.jp )

National Cancer Center Hospital

\section{Research Article}

Keywords: Biopsy, Clinical Trial, Disease Progression, Diagnostic Imaging, Therapeutics/AE

Posted Date: February 7th, 2022

DOI: https://doi.org/10.21203/rs.3.rs-1203791/v1 
License: (c) (i) This work is licensed under a Creative Commons Attribution 4.0 International License. Read Full License

Version of Record: A version of this preprint was published at Investigational New Drugs on April 11th, 2022. See the published version at https://doi.org/10.1007/s10637-022-01236-4. 


\section{Abstract}

Purpose: In first-in-human (FIH) trials, sequential tumor biopsies, i.e., two consecutive tumor biopsies, the first perfomed at baseline (pretreatment) and the second during the early treatment period (on-treatment), provide proof of concept in investigational new drugs.

Methods: We evaluated the success of sequential tumor biopsies in FIH trials, and explored approaches for improved success rates. We retrospectively reviewed the sequential tumor biopsies required in 17 of $52 \mathrm{FIH}$ trials conducted from 2015 to 2020.

Results: One hundred and thirty-eight patients were identified. Success of either pretreatment or ontreatment biopsy alone, and of sequential tumor biopsies, was defined as the acquisition of viable tumor cells and as obtaining tumor cells from both biopsy specimens, respectively. The success rates of pretreatment and on-treatment biopsy were $98.6 \%$ and $94.2 \%$, respectively, and of sequential tumor biopsies was $70.3 \%$. Adverse events associated with the pretreatment biopsies (33.3\% positive; $72.0 \%$ negative) and timing of the first imaging assessment (before on-treatment biopsy $=40.0 \%$; after ontreatment biopsy $=82.7 \%$ ) correlated with successful sequential tumor biopsies. The reasons for unsuccessful sequential tumor biopsies could be categorized into two groups: 1) patient refusal of the on-treatment biopsy (most frequently due to early disease progression); and 2) absence of tumor cells in the pretreatment or on-treatment biopsy specimen.

Conclusion: We propose an approach to achieving greater success in sequential tumor biopsies in FIH trials; the first imaging assessment during the study should be scheduled after on-treatment biopsy.

(Registration number UMIN000042487, Date of registration November 18, 2020)

\section{Introduction}

In recent decades, sequential tumor biopsies, i.e., two consecutive tumor biopsies, the first performed at baseline and the second during the early treatment period, have often been included in phase I trials, especially first-in-human $(\mathrm{FIH})$ trials, to provide proof of concept of investigational new drugs (INDs), the biologic effect of drugs on target molecules, and to assess the tumor microenvironment [1-3]. An increasing number of $\mathrm{FIH}$ trials have required sequential tumor biopsies in their protocols [4]. This practice has raised a number of issues, however, including safety and ethical concerns [5-7]. In the past three decades, several studies have focused on the performance of a single tumor biopsy at baseline in clinical trials and have reported a success rate (defined as an adequate number of viable tumor cells) of $70-90 \%[6,8-10]$. These studies also investigated the different factors affecting successful single tumor biopsies, including biopsy site, technical procedure, size of target lesion, necrosis on imaging, and operator dependence. One study investigated the success rate of sequential tumor biopsies in clinical trials at an academic medical center [11], and reported a success rate of $41.7 \%$. However, no study has analyzed why the success rate of sequential tumor biopsies is notably lower than that of a single tumor biopsy. 
Here, we evaluated our performance in FIH trials requiring sequential tumor biopsies and analyzed the detailed reasons for unsuccessful sequential tumor biopsies. We propose an approach to achieving greater success in sequential tumor biopsies in FIH trials.

\section{Materials And Methods Patient data collection}

We conducted a retrospective study of the 17 of $52 \mathrm{FIH}$ trials that required sequential tumor biopsies at the National Cancer Center Hospital (NCCH) in Tokyo from July 2015 to December 2020. We analyzed patient characteristics, including age, gender, Eastern Cooperative Oncology Group (ECOG) performance status (PS), and cancer type. The types of IND, biopsy site, technical procedure, and biopsy outcome (tumor cell acquisition, adverse events [AEs]) were also analyzed. We also evaluated the timing of the ontreatment biopsy and the first imaging assessment during the study.

\section{Definition of terms}

We defined the biopsy performed at baseline as the "pretreatment biopsy" and the biopsy performed during the early treatment period as the "on-treatment biopsy." A pretreatment biopsy or on-treatment biopsy was defined as successful if the acquisition of tumor cells in the specimen was confirmed by the designated pathologist [12]. A pair of sequential tumor biopsies was defined as successful if tumor cells were obtained from both pretreatment and on-treatment biopsy specimens. This study categorized biopsy sites as follows: skin/soft tissue (skin, subcutaneous tissue, breast, and vagina), bone/internal organs (bone, pleura, peritoneum, kidney, and mediastinum), and gastrointestinal tract (stomach, esophagus, and rectum).

We calculated the success rate of sequential tumor biopsies as the number of patients in whom both the pretreatment biopsy and the on-treatment biopsy were performed successfully per the number of patients enrolled in each $\mathrm{FIH}$ trial. We graded biopsy-related AEs according to the $\mathrm{NCI}$ Common Terminology Criteria for Adverse Events version 4.0. [13].

\section{Statistical analysis}

Univariate analysis (Fisher's exact test) and multivariate analysis (logistic regression model) were performed to examine whether any of the following three factors affected the success of sequential tumor biopsies: ECOG PS, AEs related to pretreatment biopsies, and the first imaging assessment during the study (before vs. after on-treatment biopsy). All tests were two-sided, and a $P$-value $<.05$ was considered statistically significant. All statistical analyses were performed using commercial software (JMP version 14.3; SAS Inc., Cary, North Carolina, USA).

\section{Result}

\section{Patient characteristics and biopsies}


A total of 138 patients were identified in the $17 \mathrm{FIH}$ trials (Fig. 1). The numbers of patients who underwent pretreatment and on-treatment biopsy were 138 and 103, respectively. Patient characteristics and type of IND are shown in Table 1. In terms of cancer type, lung cancer was the most common with 70 patients, followed by colorectal cancer with 13 patients. One hundred and ten patients were enrolled in trials of immuno-oncology drugs or antibody-drug conjugates. The most common biopsy sites were lung and lymph nodes (cervical, supraclavicular, mediastinal, and hilar) in both pretreatment and on-treatment biopsies (Fig. 2a and 2b). The most common technical procedures were bronchoscopy and ultrasound (US)-guided needle biopsy in both pretreatment and on-treatment biopsies. 
Table 1

a. Patient characteristics

\begin{tabular}{|ll|}
\hline Characteristic & $N(\%)$ \\
\hline Total & 138 \\
\hline Gender & $77(55.8) / 61(44.2)$ \\
\hline Male/Female & \\
\hline ECOG ${ }^{\text {Performance Status }}$ & $81(58.7) / 57(41.3)$ \\
\hline 0/1 & \\
\hline Age, years & $35(25.4) / 103(74.6)$ \\
\hline$>65 / \leq 65$ & \\
\hline Cancer type & $60(43.5)$ \\
\hline Lung cancer & $13(9.4)$ \\
\hline Colorectal cancer & $9(6.5)$ \\
\hline Pancreatic cancer & $7(5.1)$ \\
\hline Ovarian cancer & $6(4.3)$ \\
\hline Breast cancer & $6(4.3)$ \\
\hline Melanoma & $6(4.3)$ \\
\hline Sarcoma & $5(3.6)$ \\
\hline Head and neck cancer & $5(3.6)$ \\
\hline Thymic cancer & $4(2.9)$ \\
\hline Esophageal cancer & $3(2.2)$ \\
\hline Uterine cancer & $2(1.5)$ \\
\hline Bile duct cancer & $2(1.5)$ \\
\hline Kidney cancer & $2(1.5)$ \\
\hline Neuroendocrine tumor & \\
\hline Stomach cancer & \\
\hline Other & \\
\hline Type of investigational new drug & \\
\hline
\end{tabular}

Abbreviations: ${ }^{a} E C O G$; Eastern Cooperative Oncology Group 


\begin{tabular}{|ll|}
\hline Characteristic & $\mathbf{N}(\%)$ \\
\hline Immuno-oncology drug & $56(40.6)$ \\
\hline Antibody-drug conjugate & $54(39.1)$ \\
\hline Immuno-oncology drug and cytotoxic drug & $20(14.5)$ \\
\hline Molecularly targeted drug & $8(5.8)$ \\
\hline Abbreviations: ${ }^{2}$ ECOG; Eastern Cooperative Oncology Group \\
\hline
\end{tabular}

Table 1

b. Adverse events related to pretreatment biopsies and on-treatment biopsies

\begin{tabular}{|c|c|}
\hline & $N,(\%)$ \\
\hline Pretreatment biopsies & 138 \\
\hline Pneumonia (Grade ${ }^{\mathrm{a}} 3$ ) & $1(0.7)$ \\
\hline Mediastinal hemorrhage (Grade 2) & $1(0.7)$ \\
\hline Biliary fistula (Grade 2) & $1(0.7)$ \\
\hline Biopsy-related pain (Grade 2) & $1(0.7)$ \\
\hline Hemoptysis (Grade 1) & $2(1.5)$ \\
\hline None & $132(95.7)$ \\
\hline On-treatment biopsies & 104 \\
\hline Mediastinal hemorrhage (Grade 2) & $1(0.9)$ \\
\hline Fever (Grade 1) & $1(0.9)$ \\
\hline Hemoptysis (Grade 1) & $2(1.9)$ \\
\hline None & $100(96.3)$ \\
\hline \multicolumn{2}{|c|}{ Abbreviation: ${ }^{\mathrm{a} G r a d e}$; Common Terminology Criteria for Adverse Events version 4.0 Grade } \\
\hline
\end{tabular}

Pretreatment biopsy specimens from two patients did not contain tumor cells (Fig. 2a). The pretreatment biopsy in one patient was performed in the liver, while the on-treatment biopsy was performed in the lung because the pretreatment biopsy specimen did not contain tumor cells. The technical procedures used in on-treatment biopsy of three patients were changed from those used in pretreatment biopsies because of AEs related to the pretreatment biopsies: from US-guided needle biopsy to bronchoscopy $(N=1)$, from USguided needle biopsy to percutaneous biopsy $(N=1)$, and from computed tomography (CT)-guided 
needle biopsy to percutaneous biopsy $(N=1)$. Thirty-three patients did not undergo on-treatment biopsies. On-treatment biopsy specimens from six patients did not contain tumor cells, and specimens from three of these patients contained only necrotic cells, most likely due to the efficacy of the INDs (Fig. 2b).

Table 1a shows the details and $\mathrm{AE}$ rates related to pretreatment and on-treatment biopsies. The $\mathrm{AE}$ rates for pretreatment biopsy and on-treatment biopsy were $4.3 \%$ and $3.9 \%$, respectively. Lung was the biopsy site with the highest frequency of AEs for both pretreatment (7.1\%) and on-treatment biopsy (8.3\%). Bronchoscopy was the technical procedure with the highest frequency of AEs for both pretreatment (7.6\%) and on-treatment biopsies (7.5\%).

\section{Performance of sequential tumor biopsies}

The success rate of sequential tumor biopsies was $70.3 \%(95 \% \mathrm{Cl}=62.2-77.3)$ (Fig. 3a). The number of patients who had successful and unsuccessful sequential tumor biopsies is shown according to each cancer type in Fig. 3b. Pretreatment biopsies were performed in 138 patients, and the biopsy specimens from 136 patients contained tumor cells. Thirty-three patients refused on-treatment biopsy for the following reasons: early disease progression $(N=21)$, deteriorated physical condition due to AEs with INDs $(N=8)$, AEs related to the pretreatment biopsies $(N=3)$ and absence of a biopsiable lesion due to tumor shrinkage $(N=1)$. On-treatment biopsies were performed in 103 patients, and the biopsy specimens from 97 patients contained tumor cells.

\section{Timing of the first imaging assessment on successful sequential tumor biopsies}

We examined whether the timing of the first imaging assessment during the study affected successful sequential tumor biopsy in Fig. 3c. The first imaging assessments were performed before on-treatment biopsies in 40 patients ( 6 patients according to the protocol schedule and 34 patients for the purpose of evaluating AEs). Of these 40 patients, successful sequential tumor biopsy was performed in 16 patients $(40.0 \%[95 \% \mathrm{Cl}=26.3-55.4])$. Nineteen patients refused on-treatment biopsy due to early disease progression confirmed on imaging $(N=17)$ or clinical symptoms $(N=2)$. Four patients refused ontreatment biopsy for the following reasons: deteriorated conditions due to AEs with INDs $(N=3)$ and mediastinal hemorrhage (Grade 2$)$ related to the pretreatment biopsy $(N=1)$. The first imaging assessments were not performed between pretreatment biopsy and on-treatment biopsy in 98 patients. Of these 98 patients, successful sequential tumor biopsy was performed in 81 patients [82ه7\% $(95 \% \mathrm{Cl}=$ 74.0 to 88.9)]. Ten patients refused on-treatment biopsy for the following reasons: deteriorated condition due to AEs from INDs $(N=5)$, early disease progression confirmed on clinical symptoms $(N=2)$, the AE of biopsy-related pain (Grade 2 ) and pneumonia (Grade 3 ) related to the pretreatment biopsy $(N=2)$, and absence of a biopsiable lesion due to tumor shrinkage $(N=1)$.

\section{Factors correlating with success of sequential tumor biopsies and tumor biopsy sampling}


Patient characteristics, including ECOG PS, did not affect successful sequential tumor biopsy (Table 2). AEs related to pretreatment biopsy (33.3\% positive; $72.0 \%$ negative) did not affect successful sequential tumor biopsy in univariate analysis $(P=0.0639)$, but did in multivariate analysis $(P=.0057)$. The timing of the first imaging assessment during the study (before on-treatment biopsy $=40.0 \%$; after on-treatment biopsy $=82.7 \%$ ) had a major impact on successful sequential tumor biopsies in both univariate and multivariate analysis, with $P<.0001$ in both.

Table 2

Univariate and multivariate analysis of successful sequential tumor biopsy by ECOG Performance Status, adverse events related to pretreatment biopsy, and timing of the first imaging assessment

\begin{tabular}{|llll|}
\hline Factor & $\begin{array}{l}\text { Successful sequential } \\
\text { tumor biopsy } \\
\text { N, (\%) }\end{array}$ & $\begin{array}{l}\text { Univariate } \\
\text { analysis }\end{array}$ & $\begin{array}{l}\text { Multivariate } \\
\text { analysis }\end{array}$ \\
\hline ECOG ${ }^{\text {Performance Status }}$ & & $P=.248$ & $P=.259$ \\
\hline 0 & $60 / 81(74.1 \%)$ & & \\
\hline 1 & $37 / 57(64.9 \%)$ & $P=.0639$ & $P=.0057$ \\
\hline $\begin{array}{l}\text { Adverse events related to } \\
\text { pretreatment biopsy }\end{array}$ & $2 / 6(33.3 \%)$ & & \\
\hline Yes & $95 / 132(72.0 \%)$ & $P<.0001$ & $P<.0001$ \\
\hline No & & & \\
\hline $\begin{array}{l}\text { Timing of the first imaging } \\
\text { assessment }\end{array}$ & $16 / 40(40.0 \%)$ & & \\
\hline Before on-treatment biopsy & $81 / 98(82.7 \%)$ & & \\
\hline After on-treatment biopsy & & & \\
\hline Abbreviations: ${ }^{a}$ ECOG; Eastern Cooperative Oncology Group & & \\
\hline
\end{tabular}

\section{Discussion}

Sequential tumor biopsies in FIH trials play a key role in providing proof of concept of the mechanism of action of INDs. The difficulty of achieving success with sequential tumor biopsies has been reported [11, 14]. However, no report has suggested approaches to overcome this difficulty. We evaluated our performance of sequential tumor biopsies in the FIH trials and explored approaches for a higher success rate.

Our study shows that the success rate of sequential tumor biopsies in $\mathrm{FIH}$ trials was as high as $70.3 \%$. The fact that all patients underwent pretreatment biopsy after enrollment in the $\mathrm{FIH}$ trials suggests that these patients were prepared to undergo tumor biopsy sampling as required in the protocols, and that none revoked an earlier agreement to participate on learning of the protocol necessity for biopsy, as has 
been reported elsewhere $[6,10,15]$. In both pretreatment and on-treatment biopsies, the success rate of tumor biopsy sampling was considered to be higher than that generally reported, and the rate of biopsyrelated AEs was considered lower $[9,11,14]$. AEs related to the pretreatment biopsies were negatively associated with the completion of successful sequential tumor biopsies (Table 2). In selecting biopsy site and type of technical procedure, it is important to maximize the possibility of tumor cells being obtained in the biopsy specimen, but also to minimize the possibility of biopsy-related AEs $[16,17]$. The success rate of on-treatment biopsy (94.2\%) was slightly lower than that of pretreatment biopsy (98.6\%) $(P$ $=.0763$ ). This was partly related to necrosis in the on-treatment biopsy specimens due to the efficacy of the IND in three patients.

There was a discordance between our success rate in sequential tumor biopsies (70.3\%) and the success rate of pretreatment $(98.6 \%)$ and on-treatment biopsies (94.2\%), respectively. The major reason for this discordance was the patients' refusal of on-treatment biopsy $(N=33)$, and 21 out of 33 refusal $(63.6 \%)$ were related to early disease progression. On-treatment biopsies could not be performed when the patients felt distressed due to early disease progression, even though the biopsy target lesions were larger and easier to biopsy $[8,9]$. The American Society of Clinical Oncology has published clear guidelines on tumor biopsy sampling in early-phase clinical trials [18], with the core ethical principles of minimizing risk for participants.

Liquid biopsy is less invasive to the patient than tissue biopsy $[19,20]$. Patients would most likely be willing to consent to a blood draw, instead of a painful biopsy procedure, even in the presence of early disease progression. As the number of phase I trials in which patients can participate based on the results of liquid biopsy is increasing, liquid biopsy may be able to replace invasive tumor biopsies [21]. However, liquid biopsy faces barriers in completely replacing tissue biopsy as a means of elucidating the proof of concept of an IND, since it cannot be used to evaluate the microenvironment around the tumor [22].

The success rate of sequential tumor biopsies was significantly lower when the first imaging assessment was performed before the on-treatment biopsy (40.0\%) compared to when it was performed after the ontreatment biopsy (82.7\%). Patients inevitably refused on-treatment biopsies once the imaging assessments reveal early disease progression. In our study, the first imaging assessments were performed in 40 patients before on-treatment biopsies, and revealed early disease progression confirmed on imaging in 17 patients. All 17 of these patients refused on-treatment biopsies. The first imaging assessment during the study should be scheduled after on-treatment biopsy in the protocol. The first imaging assessments were actually performed before on-treatment biopsy in 6 patients according to the protocol schedule in our study. If imaging assessment was scheduled after on-treatment biopsy in the protocol, the success rate of sequential tumor biopsies could be estimated to improve from $70.3-74.6 \%$. Selecting patients on similar IND protocols but on different imaging schedules would have been a technique to eliminate imaging schedule as a variable. 
In conclusion, our research showed that the success rate of sequential tumor biopsy in FIH trial was as high as $70.3 \%$. We analyzed the detailed reasons for unsuccessful sequential tumor biopsy. We propose a reasonable approach to achieve greater success in sequential tumor biopsy in FIH trials; the first imaging assessment during the study could be recommended to be scheduled after on-treatment biopsy.

\section{Declarations}

\section{Ethics approval and consent to participate}

All procedures performed in studies involving human participants were in accordance with the ethical standards of institutional Review Board of National Cancer Center Hospital (approval no: 2014-148) and with the 1964 Helsinki declaration and its later amendments or with comparable ethical standards. Informed consent was obtained in the form of optout on the website and bulletin board of our hospital.

\section{Consent for publication}

Not applicable.

\section{Availability of data and material}

The datasets supporting the conclusion of this article are included within the article.

\section{Competing interests}

All authors declare neither financial interest that is relevant to the submitted work.

\section{Funding}

The authors received no financial support for the research.

\section{Author contributions}

TK, TS, JS, YK, and NY: Conceptualization, methodology, investigation, writing the original draft, and revising the manuscript.

SI, SK, TY, KS, MN, YT, and KY: Investigation and revision of the manuscript.

\section{Acknowledgment}

We thank Libby Cone, MD, MA, from DMC Corp. (www.dmed.co.jp <http://www.dmed.co.jp/>) for editing drafts of this manuscript.

\section{Compliance with Ethical Standards}


Dr. Koyama has reported receiving personal fees from Chugai and Sysmex, and grants from PACT Pharma outside the submitted work.

Dr. Shimizu has reported grants from Novartis, grants from Eli Lilly, grants from Daiichi-Sankyo, grants from Bristol-Myers Squibb, grants from Eisai, grants from AbbVie, grants from AstraZeneca, grants from Takeda Oncology, grants from Incyte, grants from Chordia Therapeutics, grants from 3D-Medicine, grants from Symbio Pharmaceuticals, grants from PharmaMar, grants from Five Prime, grants from Astellas Pharma, personal fees from Taiho Pharmaceuticals, personal fees from Boehringer Ingelheim, personal fees from Chugai Pharmaceuticals, personal fees from ONO Pharmaceuticals, personal fees from Takeda Pharmaceuticals, personal fees from AbbVie, grants from Pfizer, and personal fees from Daiichi-Sankyo outside the submitted work.

Dr. Sato has nothing to disclose.

Dr. Katsuya has nothing to disclose.

Dr. Iwasa has reported grants from Bristol Myers Squibb, grants from Bayer, grants from Eisai, and grants from Ono Pharmaceutical Co., Ltd. outside the submitted work.

Dr. Kondo has reported research funding from ASLAN Pharmaceuticals, AstraZeneca, Bayer, Eli Lilly, MSD, $\mathrm{Bl}$, and Pfizer outside the submitted work.

Dr. Yoshida has reported grants from Ono Pharmaceutical, grants from Bristol-Myers Squibb, grants from Takeda, personal fees from Chugai, personal fees from Novartis, grants, and personal fees from AstraZeneca, grants and personal fees from MSD, and personal fees from ArcherDX outside the submitted work.

Dr. Sudo has reported personal fees from AstraZeneca and personal fees from Pfizer outside the submitted work.

Dr. Nishino has reported personal fees from Astra Zeneca, personal fees from Bristol-Myers Squibb, personal fees from Boehringer Ingelheim Japan, personal fees from Chugai, personal fees from Eli Lilly, personal fees from MSD, personal fees from ONO Pharmaceutical, and personal fees from Taiho outside the submitted work.

Dr. Takiguchi has reported grants and personal fees from Eli Lilly, grants and personal fees from Chugai Pharmaceutical Co, grants and personal fees from MSD, grants and personal fees from Taiho pharmaceutical Co, grants and personal fees from Novartis, grants and personal fees from Boehringer Ingelheim, grants and personal fees from Ono Pharmaceutical Co., grants from Takeda, grants from Daiichi Sankyo, grants from Kyowa-Hakko Kirin, and personal fees from AstraZeneca outside the submitted work 
Dr. Yonemori has reported personal fees from Eisai, personal fees from Pfizer, personal fees from AstraZeneca, personal fees from Takeda, personal fees from Taiho, and personal fees from Chugai outside the submitted work.

Dr. Yamamoto has reported grants from Chugai, grants from Taiho, grants from Eisai, grants from Lilly, grants from Quintiles, grants from Astellas, grants from BMS, grants from Novartis, grants from DaiichiSankyo, grants from Pfizer, grants from Boehringer Ingelheim, grants from Kyowa-Hakko Kirin, grants from Bayer, grants from ONO PHARMACEUTICAL CO., LTD, grants from Takeda, personal fees from ONO PHARMACEUTICAL CO., LTD, personal fees from Chugai, personal fees from AstraZeneca, personal fees from Pfizer, personal fees from Lilly, personal fees from BMS, personal fees from Eisai, personal fees from Otsuka, personal fees from Takeda, personal fees from Boehringer Ingelheim, personal fees from Cimic, grants from Janssen Pharma, grants from MSD, grants from Merck, personal fees from Sysmex, grants from GSK, and grants from Sumitomo Dainippon, grants from Chiome Bioscience Inc. outside the submitted work.

\section{Research involving Human Participants and/or Animals}

All procedures performed in studies involving human participants were in accordance with the ethical standards of institutional Review Board of National Cancer Center Hospital (approval no: 2014-148) and with the 1964 Helsinki declaration and its later amendments or with comparable ethical standards.

\section{Informed consent}

Informed consent was obtained in the form of optout on the website and bulletin board of our hospital.

\section{References}

1. Kummar S, Do K, Coyne GO, Chen A, Ji J, Rubinstein L, Doroshow JH (2016) Establishing proof of mechanism: Assessing target modulation in early-phase clinical trials. Semin Oncol 43(4):446-452. doi:10.1053/j.seminoncol.2016.06.002

2. Lim C, Tsao MS, Le LW, Shepherd FA, Feld R, Burkes RL, Liu G, Kamel-Reid S, Hwang D, Tanguay J, da Cunha Santos G, Leighl NB (2015) Biomarker testing and time to treatment decision in patients with advanced nonsmall-cell lung cancer. Ann Oncol 26(7):1415-1421. doi:10.1093/annonc/mdv208

3. Gastman B, Agarwal PK, Berger A, Boland G, Broderick S, Butterfield LH, Byrd D, Fecci PE, Ferris RL, Fong Y, Goff SL, Grabowski MM, Ito F, Lim M, Lotze MT, Mahdi H, Malafa M, Morris CD, Murthy P, Neves RI, Odunsi A, Pai SI, Prabhakaran S, Rosenberg SA, Saoud R, Sethuraman J, Skitzki J, Slingluff CL, Sondak VK, Sunwoo JB, Turcotte S, Yeung CC, Kaufman HL (2020) Defining best practices for tissue procurement in immuno-oncology clinical trials: consensus statement from the Society for Immunotherapy of Cancer Surgery Committee. J Immunother Cancer 8(2). doi:10.1136/jitc-2020001583 
4. Parseghian CM, Tam AL, Yao J, Ensor J Jr, Ellis LM, Raghav K, Overman MJ (2019) Assessment of Reported Trial Characteristics, Rate of Publication, and Inclusion of Mandatory Biopsies of Research Biopsies in Clinical Trials in Oncology. JAMA Oncol 5(3):402-405. doi:10.1001/jamaoncol.2018.4640

5. Kimmelman J, Resnik DB, Peppercorn J, Ratain MJ (2017) Burdensome Research Procedures in Trials: Why Less Is More. J Natl Cancer Inst 109(4). doi:10.1093/jnci/djw315

6. El-Osta H, Hong D, Wheler J, Fu S, Naing A, Falchook G, Hicks M, Wen S, Tsimberidou AM, Kurzrock R (2011) Outcomes of research biopsies in phase I clinical trials: the MD anderson cancer center experience. Oncologist 16(9):1292-1298. doi:10.1634/theoncologist.2011-0043

7. Biondo A, Pal A, Riisnaes R, Shinde R, Tiu C, Lockie F, Baker C, Bertan C, Crespo M, Ferreira A, Pereira R, Figueiredo I, Miranda S, Gurel B, Carreira S, Banerji U, de Bono J, Lopez J, Tunariu N, Minchom A (2021) Research Related Tumour Biopsies in Early-Phase Trials with Simultaneous Molecular Characterisation - a Single Unit Experience. Cancer Treat Res Commun 27:100309. doi:10.1016/j.ctarc.2021.100309

8. Sabir SH, Krishnamurthy S, Gupta S, Mills GB, Wei W, Cortes AC, Mills Shaw KR, Luthra R, Wallace MJ (2017) Characteristics of percutaneous core biopsies adequate for next generation genomic sequencing. PLoS ONE 12(12):e0189651. doi:10.1371/journal.pone.0189651

9. Tacher V, Le Deley MC, Hollebecque A, Deschamps F, Vielh P, Hakime A, lleana E, Abedi-Ardekani B, Charpy C, Massard C, Rosellini S, Gajda D, Celebic A, Ferte C, Ngo-Camus M, Gouissem S, Koubi-Pick V, Andre F, Vassal G, Deandreis D, Lacroix L, Soria JC, De Baere T (2016) Factors associated with success of image-guided tumour biopsies: Results from a prospective molecular triage study (MOSCATO-01). Eur J Cancer 59:79-89. doi:10.1016/j.ejca.2016.02.006

10. Gomez-Roca CA, Lacroix L, Massard C, De Baere T, Deschamps F, Pramod R, Bahleda R, Deutsch E, Bourgier C, Angevin E, Lazar V, Ribrag V, Koscielny S, Chami L, Lassau N, Dromain C, Robert C, Routier E, Armand JP, Soria JC (2012) Sequential research-related biopsies in phase I trials: acceptance, feasibility and safety. Ann Oncol 23(5):1301-1306. doi:10.1093/annonc/mdr383

11. Lee K, Lee SJ, Yoon S, Ryoo BY, Kim SW, Choi SH, Lee SM, Chae EJ, Park Y, Jang SJ, Park SY, Yoon YK, Park SH, Kim TW (2019) Feasibility, safety, and adequacy of research biopsies for cancer clinical trials at an academic medical center. PLoS ONE 14(8):e0221065. doi:10.1371/journal.pone.0221065

12. Tokaca N, Barth S, O'Brien M, Bhosle J, Fotiadis N, Wotherspoon A, Thompson L, Popat S (2018) Molecular Adequacy of Image-Guided Rebiopsies for Molecular Retesting in Advanced Non-Small Cell Lung Cancer: A Single-Center Experience. J Thorac Oncol 13(1):63-72. doi:10.1016/j.jtho.2017.09.1958

13. Common (2009) Terminology criteria for adverse events (CTCAE) version 4.03

14. Ferry-Galow KV, Chen AP (2019) The use of research biopsies in oncology trials: challenges and controversies. J Hosp Manag Health Policy 3. doi:10.21037/jhmhp.2019.03.01

15. Cheng JH, Tiulim JW, Zhou S, El-Khoueiry A, Nieva J (2019) Mandatory Research Biopsy Requirements Delay Initiation of Clinical Trials. Front Oncol 9:968. doi:10.3389/fonc.2019.00968 
16. Sone M, Arai Y, Sugawara S, Kubo T, Itou C, Hasegawa T, Umakoshi N, Yamamoto N, Sunami K, Hiraoka N, Kubo T (2019) Feasibility of genomic profiling with next-generation sequencing using specimens obtained by image-guided percutaneous needle biopsy. Ups J Med Sci 124(2):119-124. doi:10.1080/03009734.2019.1607635

17. von Itzstein MS, Gupta A, Mara KC, Khanna S, Gerber DE (2019) Increasing Numbers and Reported Adverse Events in Patients with Lung Cancer Undergoing Inpatient Lung Biopsies: A PopulationBased Analysis. Lung 197(5):593-599. doi:10.1007/s00408-019-00255-y

18. Levit LA, Peppercorn JM, Tam AL, Marron JM, Mathews DJH, Levit K, Roach N, Ratain MJ (2019) Ethical Framework for Including Research Biopsies in Oncology Clinical Trials: American Society of Clinical Oncology Research Statement. J Clin Oncol 37(26):2368-2377. doi:10.1200/jco.19.01479

19. Corcoran RB, Chabner BA (2018) Application of Cell-free DNA Analysis to Cancer Treatment. N Engl J Med 379(18):1754-1765. doi:10.1056/NEJMra1706174

20. Wan JCM, Massie C, Garcia-Corbacho J, Mouliere F, Brenton JD, Caldas C, Pacey S, Baird R, Rosenfeld N (2017) Liquid biopsies come of age: towards implementation of circulating tumour DNA. Nat Rev Cancer 17(4):223-238. doi:10.1038/nrc.2017.7

21. Rothwell DG, Ayub M, Cook N, Thistlethwaite F, Carter L, Dean E, Smith N, Villa S, Dransfield J, Clipson A, White D, Nessa K, Ferdous S, Howell M, Gupta A, Kilerci B, Mohan S, Frese K, Gulati S, Miller C, Jordan A, Eaton H, Hickson N, O'Brien C, Graham D, Kelly C, Aruketty S, Metcalf R, Chiramel J, Tinsley N, Vickers AJ, Kurup R, Frost H, Stevenson J, Southam S, Landers D, Wallace A, Marais R, Hughes AM, Brady G, Dive C, Krebs MG (2019) Utility of ctDNA to support patient selection for early phase clinical trials: the TARGET study. Nat Med 25(5):738-743. doi:10.1038/s41591-019-0380-z

22. Lara OD, Krishnan S, Wang Z, Corvigno S, Zhong Y, Lyons Y, Dood R, Hu W, Qi L, Liu J, Coleman RL, Westin SN, Fleming ND, Cristini V, Rao A, Burks J, Sood AK (2019) Tumor core biopsies adequately represent immune microenvironment of high-grade serous carcinoma. Sci Rep 9(1):17589. doi:10.1038/s41598-019-53872-1

\section{Figures}


138 patients included in 17 first-in-human trials requiring sequential tumor biopsy

138 patients underwent pretreatment biopsy

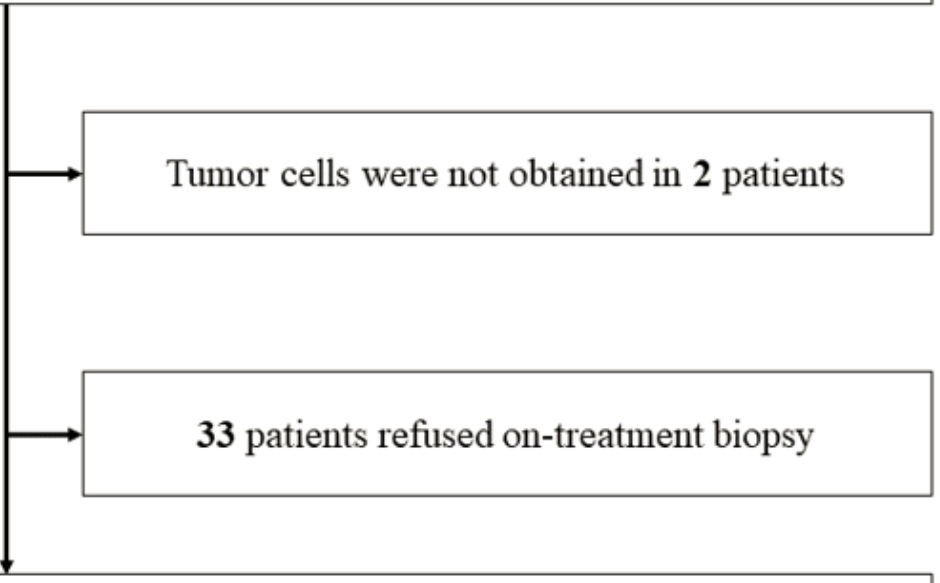

103 patients underwent on-treatment biopsy

Figure 1

\section{Patient flow diagram}

All 138 patients who were enrolled in 17 oncology first-in-human trials that required sequential biopsies underwent pretreatment biopsies. Two patients had no tumor cells in the pretreatment biopsies. Thirtythree patients refused on-treatment biopsy, with 103 patients undergoing on-treatment biopsies.

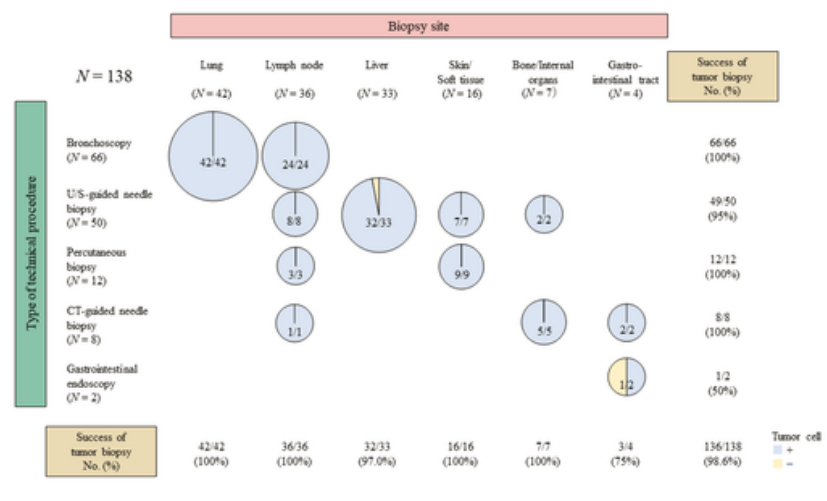

(a)

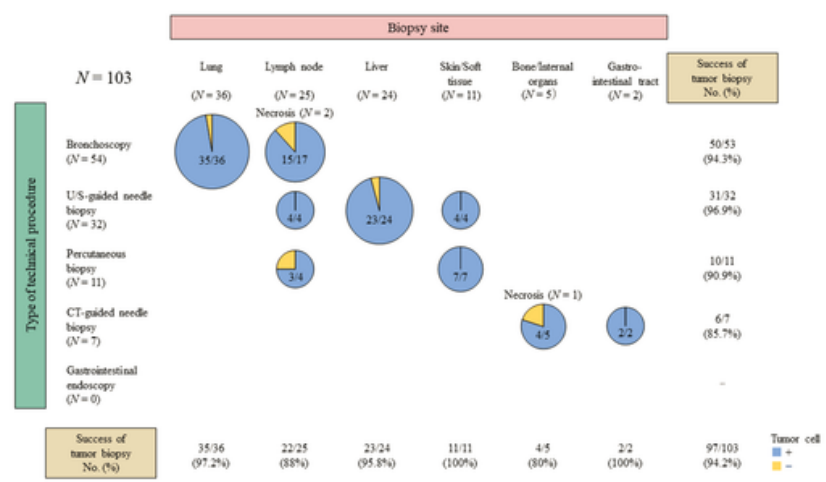

(b)

Figure 2 


\section{a Biopsy site and technical procedure in pretreatment biopsy}

Each pretreatment biopsy and on-treatment biopsy were defined as successful if the acquisition of adequate tumor cells in the specimen were confirmed by the designated pathologist. This study categorized biopsy sites as follows; skin/soft tissue (skin, subcutaneous tissue, breast, and vagina), bone/internal organ (bone, pleural membrane, peritoneal membrane, kidney, and mediastinum), and gastrointestinal tract (stomach, esophagus, and rectum). The success rate of tumor biopsy sampling in the pretreatment biopsy was $98.6 \%$.

\section{b Biopsy site and technical procedure in on-treatment biopsy}

The success rate of tumor biopsy sampling in the on-treatment biopsy was $94.2 \%$. On-treatment biopsy specimens from six patients did not contain tumor cells, and specimens from three of these patients contained only necrotic cells, most likely due to the efficacy of the INDs revealed necrosis based on evaluation of H\&E-stained slides by pathological diagnosis.

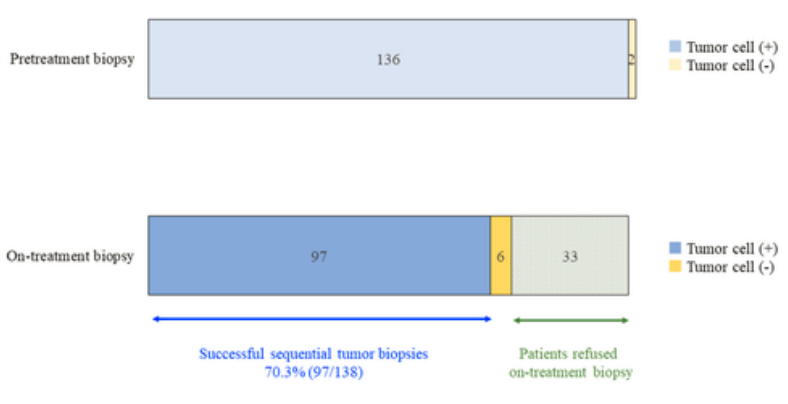

(a)

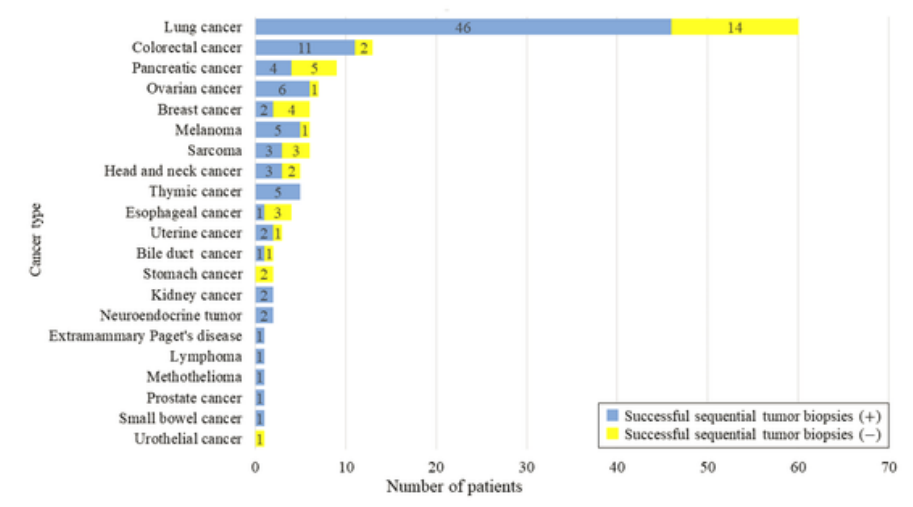

(b)

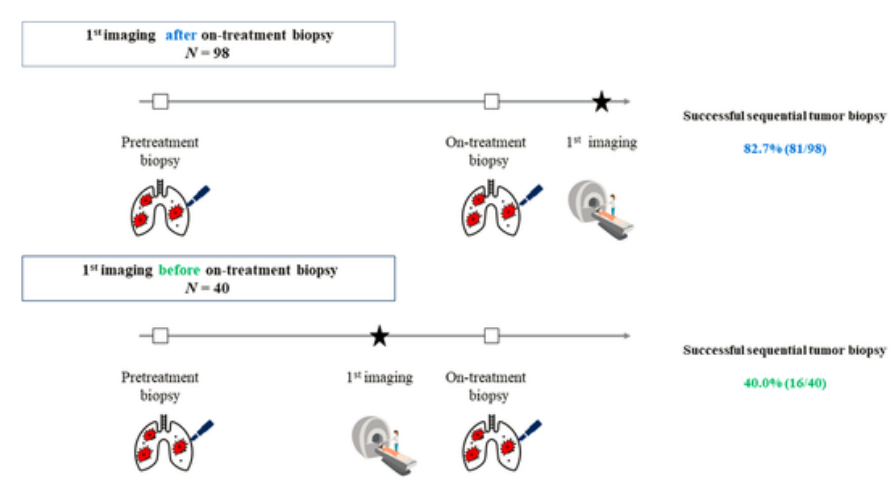

(c)

\section{Figure 3}

\section{a Success of sequential tumor biopsy}


The sequential tumor biopsies were defined as successful if tumor cells were obtained from both pretreatment and on-treatment biopsy specimens. The success rate of sequential tumor biopsies was 70.3\%. All 138 patients who were enrolled in 17 first-in-human trials underwent pretreatment biopsy ( $N=$ 138). An on-treatment biopsy was not carried out in 33 patients because of the patients' refusal. A total of 103 underwent on-treatment biopsy, with 97 biopsies considered successful.

\section{b Successful sequential tumor biopsy by cancer type}

The number of patients who had successful sequential tumor biopsies and the number of patients who did not have successful sequential tumor biopsies by cancer type are shown.

\section{c Impact of $1^{\text {st }}$ tumor imaging timing on successful sequential tumor biopsy}

Of the forty-three patients undergoing the first imaging assessment before on-treatment biopsy, 16 patients subsequently underwent on-treatment biopsy (41.0\%). The first imaging assessments were not performed between pretreatment biopsy and on-treatment biopsy in 95 patients. Of these 99 patients, successful sequential tumor biopsies were performed in 81 patients $(81.8 \%)$.

\section{Supplementary Files}

This is a list of supplementary files associated with this preprint. Click to download.

- Supplementsequentialtumorbiopsy.pdf 